\title{
FAKTOR INTERNAL PENENTU LAJU PERTUMBUHAN MODAL SENDIRI PADA PERUSAHAAN ROKOK GO PUBLIC DI BURSA EFEK INDONESIA
}

Submitted Date :

27 November 2020

Accepted Date :

29 November 2020
Wahyu Wiyani

Universitas Merdeka Malang

wahyu.wiyani@unmer.ac.id

Eko Yuni Prihantono

Universitas Merdeka Malang

eko.prihantono@unmer.ac.id

Roos Widjajani

Universitas Merdeka Malang

rooswidjajani@unmer.ac.id

Harril Brimantyo

Universitas Merdeka Malang

harril.brimantyo@unmer.ac.id

\section{Suggested Citation:}

Rosana, Ruth. (2010) Analisis faktor-faktor yang mempengauhi pertumbuhan modal sendiri pada perusahaan real estate \& building construction, Jurnal Ekonomi Vol 12 No 3 Juli 2010. USU, Medan. repository.USU.ac.id

Abstract:

This study aims to analyze the effect of the basic earning power, debt to equity ratio, plowback ratio, and interest and tax rate on the growth rate of equiy in cigarette companies that go public on the Indonesia Stock Exchange in 2013-2018. Data analysis technique used is multiple linear regression. The results showed that the four variables had a simultaneously significant effect on the growth rate of equity, while only Basic Earning Power had no significant effect partially. Because the calculation of basic earning power uses Earning Before Interest and Tax where Earning Before Interest and Tax is the profit that has not been taxed, which in fact tax for cigarette companies is a large expense. In addition, equity growth itself is largely determined by the amount of Earning After Tax compared to Earning Before Interest and Tax. The higher the Earning After Tax, the greater the opportunity for equity growth.

Keywords: basic earning power, capital growth rate, debt to equity ratio, interest and tax rate, plowback ratio

\section{Abstrak:}

Penelitian ini bertujuan untuk menganalisis pengaruh variabel basic earning power, debt to equity ratio, plowback ratio, serta interest and tax rate terhadap laju pertumbuhan modal sendiri pada perusahaan rokok yang go public di Bursa Efek Indonesia tahun 2013-2018. Teknik analisis data yang digunakan adalah regresi linier berganda. Hasil penelitian menunjukkan secara simultan keempat variabel berpengaruh secara signifikan terhadap laju pertumbuhan modal sendiri, sementara secara parsial yang tidak berpengaruh secara signifikan hanya basic earning power. Karena perhitungan basic earning power menggunakan earning before interest and tax dimana merupakan laba yang belum terkena pajak yang notabene pajak bagi perusahaan rokok adalah pengeluaran yang besar. Selain itu pertumbuhan modal sendiri sangat ditentukan besarnya earning ater tax dibanding dengan earning before interest and tax. Semakin tinggi earning ater tax akan memberikan peluang pertumbuhan modal aendiri yang besar.

Kata Kunci: basic earning power, capital growth rate, debt to equity ratio, interest and tax rate, plowback ratio

JEL Classification : G32, M19

${ }^{*}$ Corresponding Author 
Volume 7, No 2 (197 - 203), 2020 lenovo

\section{Latar Belakang}

Memasuki era globalisasi, perkembangan teknologi informasi sangat pesat. Seiring engan perkembangan dan kemajuan teknologi informasi mengakibatkan terjadinya persaingan yang ketat antar perusahaan. Adanya persaingan tersebut memasa perusahaan untuk meningkatkan kinerjanya sehngga mampu mencapai tujuan utama dari usahanya, yaitu memperoleh laba yang maksimal. Dengan menghasilkan laba, perusahaan dapat mempertahankan pertumbuhan perusahaannya sehingga dapat bersaing dengan perusahaan lain karena laba tersebut dapat ditanam kembali dan digunakan untuk mempertahankan atau meningkatkan pertumbuhannya.

Pertumbuhan perusahaan sering dipakai sebagai tolak ukur dalam menilai perkembangan suatu perusahaan. Di dalam dunia bisnis, pengertian pertumbuhan menunjukan semakin meningkatnya ukuran dan aktivitas perusahaan dalam jangka panjang. Pertumbuhan perusahaan dapat diukur dengan beberapa cara, misalnya dengan melihat pertumbuhan yang disebabkan oleh aspek pemasaran perusahaan. Pengukuran yang lain adalah dengan melihat pertumbuhan laba operasi perusahaan. Dengan melakukan pengukuran pertumbuhan laba operasi perusahaan, kita dapat melihat aspek pemasaran perusahaan, dan efiseinsi perusahaan. Pengukuran yang lebih lengkap selain pengukuran pertumbuhan laba operasi perusahaan adalah pengukuran pertumbuhan laba bersih perushaan dengan menambah efisiensi penggunaan modal, dimana inputnya adalah modal dan outpuntya berupa laba. Pengukuran berikutnya adalah pengukuran pertumbuhan modal sendiri, yang mempertimbangkan baik keputusan investasi (investment decision, dan keputusan pembiayaan (financing decision), serta dengan memperhatikan faktor yang berupa tingkat bunga pinjaman dan tingkat pajak. Pengukuran yang paling dapat menggambarkan pertumbuhan modal yang lebih tepat adalah dengan menambahkan keputusan pemberian deviden, selain faktor investment decision, financing decision, tingkat bunga dan tingkat pajak.

Pertumbuhan modal sendiri perusahaan merupakkan hasil persentase dari peningkatan modal sendiri dibandingkan dengan jumlah modal sendiri sebelumnya (Maryati, 2001). Suatu perusahaan yang mempunyai laju pertumbuhan tinggi akan mempunyai modal yang cukup untuk membiayai pertumbuhannya tersebut. Makin cepat tingkat atau laju pertumbuhan perusahaan, maka makin besar kebutuhan untuk membelanjai pertumbuhan perusahaan tersebut. Makin besar kebutuhan dana untuk membelanjai pertumbuhannya maka perusahaan tersebut makin cenderung untuk menahan sebagian besar dari keuntungan yang diperoleh. Menurut Brigham (2006:184), faktor - faktor yang mempengaruhi pertumbuhan modal sendiri adalah basic erning power (EP), debt to equity ratio (DER), plowback ratio (PR), interest and tax rate (ITR). Penelitian ini akan menganalisis pengaruh faktor - faktor seperti basic earning power (EP), debt to equity ratio (DER), plowback ratio/retention rate (PR) serta interet and tax rate (ITR) terhadap pertumbuhan modal sendiri.

Basic earning power (EP) merupakan salah satu raso profitabilitas yang dapat mengukur kemampuan perusahaan dalam menghasilkan laba dari aktiva yang digunakan. Basic earning power (EP) merupakan perbandingan antara laba sebelum bunga dan pajak (EBIT) dengan total aktiva yang dimiliki perusahaan. Basic erning power $(E P)$ yang positif menunjukkan bahwa dari total aktiva yang dipergunakan untuk beroperasi, perusahaan mampu memberian laba bagi perusahaan. Sebaliknya apabila basic earning power (EP) yang negative menunjukkan bahwa dari total aktiva yang dipergunakan, perusahaan mengalami kerugian. Jadi jika suatu perusahaan mempunyai basic earning power (EP) yang tinggi maka perusahaan tersebut berpeluang besar dalam meningkatkan pertumbuhan modal sendiri, karena perusahaan memperoleh keuntungan yang akan menambah modalnya. Tetapi jika total aktiva yang digunakan perusahaan tidak memberikan laba maka perusahaan akan mengalami kerugian dan akan menghambat pertumbuhan modal sendiri.

Debt to equity ratio (DER) merupakan salah satu rasio leverage yang dapat menunjukkan kemampuan modal sendiri untuk memenuhi seluruh kewajibannya. Karena debt to equity ratio (DER) juga menunjukkan seberapa besar struktur finansial perusahaan berasal dari hutang, maka tinggi rendahnya debt to equity ratio (DER) juga menggambarkan besar kecilnya jumlah hutang dalam perusahaan. Hutang perusahaan tersebut diharapkan dapat digunakan untuk menambah dana perusahaan guna memperluas kegiatan operasionalnnya. Plowback ratio (PR) merupakan tingkat keuntungan yang tidak dibagikan kepada pemegang saham sebagai dividen. Laba yang tidak dibagikan ini akan menambah jumlah modal sendiri dan berpengaruh positif terhadap pertumbuhan modal sendiri. Faktor lain yang akan dianalisis pengaruhannya terhadap pertumbuhan modal sendiri addalah interest and tax rate (ITR). Tingkat bunga dan pajak merupakan besarnya biaya bunga dan pajak yang harus dibayar oleh perusahaan dalam satu tahun. 


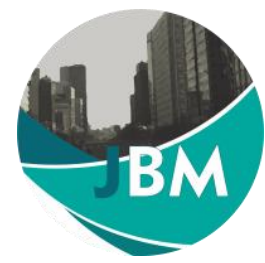

Perusahaan yang mengharapkan laju pertumbuhan tinggi, harus menyediakan modal yang cukup untuk membiayai pertumbuhan perusahaan yang diinginkn tersebut. Lebih cepat laju pertumbuhan yang diinginkan, makin besar kebutuhan dana untuk membiayainya. Perushaan yang mengharapkan pertumbuhan lebih cepat akan menahan sebagaian labanya untuk kebutuhan opersional perusahaan. Laba ditahan ini merupakan sumber modal sendiri, karena jika menggunakan modal asing, maka perusahaan akan dihadapkan pada resiko biaya bunga akan yang ditanggung oleh perusahaan. Demikian halnya dengan perusahaan rokok. Perusahaan rokok merupakan perusahaan konsumsi yang dibutuhkan hampir seluruh masyarakat Indonesia. Sehingga perusahaan rokok membutuhkan pendanaan yang tinggi, dan penggunaan modal sendiri sebagai sumber pendanaan akan menekan resiko yang akan ditanggung oleh perusahaan, misalnya tingkat suku bunga pinjaman. Dengan memahami fakrot faktor yang mempengaruhi pertumbuhan modal sendiri pihak manajemen harus mengelola keuangan perusahaan dengan cerdas agar keuntungan perusahaan bisa ditingkatkan yang secara langsung akan meningkatkan modal sendiri. Dalam penelitian ini tujuan yang hendak dicapai adalah menganalisis pengaruh faktor internal terhadap laju pertumbuhan modal sendiri.

\section{Kajian Literatur}

\section{Modal Sendiri}

Pengelolaan keuangan perusahaan yang cerdas sangat penting agar terjadi efisiensi dan efektifitas penggunaan dana. Efisiensi penggunaan dana secara langsung akan menentukan besar kecilnya tingkat keuntungan yang dihasilkan. Hal ini mengandung makna bahwa kebutuhan modal bagi tiap perusahaan adalah sangat penting. Karena untuk menjalankan usahanya tanpa didukung tersedianya faktor produksi modal yang cukup tidak akan berjalan dengan lancar.

Munawir (2010) menyebutkan modal adalah hak atau bagian yang dimiliki oleh pemilik perusahaan yang ditunjukkan dalam pos modal (modal saham), surplus dan laba yang ditahan, atau kelebihan nilai aktiva yang dimiliki oleh perusahaan terhadap seluruh utang-utangnya. Modal sendiri adalah modal yang berasal dan pemilik perusahaan yang tertanam di dalam perusahaan untuk jangka waktu yang tidak tertentu larnanya (Riyanto, 2008).

\section{Pertumbuhan Modal Sendiri}

Manajemen keuangan memiliki porsi yang sangat besar dalam suksesnya suatu perusahaan, dengan pengelolaan yang baik atas struktur permodalan dan pengalokasian modal maka stabilitas keuangan dan going concern perusahaan dapat terjamin. Setiap perusahaan memiliki struktur modal dan pengalokasian modal yang berbeda dari aspek kemampuannya untuk menghasilkan laba dan membayar kewajiban-kewajibannya atau hutang yang akan mempengaruhi kehidupan perusahaan. Stabilitas keuangan dan going concern suatu perusahaan dipengaruhi oleh pertumbuhan struktur permodalannya, salah satunya yaitu modal sendiri.

Pertumbuhan modal sendiri suatu perusahaan merupakan persentase yang menunjukkan peningkatan modal sendiri pada tahun tertentu dibandingkan jumlah modal sendiri pada tahun sebelumnya (Maryati, 2001). Perusahaan yang mengharapkan laju pertumbuhan modal yang tinggi, harus menyediakan modal yang cukup untuk membiayai pertumbuhan yang diinginkan tersebut, lebih cepat lajupertumbuhan yang diinginkan makin besar kebutuhan dana untuk membiayainya. Pertumbuhan modal sendiri fokus terhadap penciptaan nilai melalui pertumbuhan pendapatan yang menguntungkan bagi perusahaan. Pertumbuhan modal sendiri didasarkan pada asumsi dalam teori modal, yang mencakup produktifitas modal, keputusan manajer keuangan dan financial leverage.

Dalam perusahaan, modal yang produktif biasanya menggunakan hasil labanya untuk ditanamkan kembali pada modal saham, yang diperkirakan akan dapat meningkatkan persentase jumlah modal sendiri. Kondisi ini juga terkait dengan kebijakan perusahaan tentang alternatif perlakuan terhadap laba yang diperoleh, apakah akan dibagikan kepada pemegang saham dalam bentuk dividen atau diinvestasikan kembali dalam bentuk laba ditahan. 


\section{Faktor-Faktor Yang Mempengaruhi Pertumbuhan Modal Sendiri}

Menurut Brigham (1996), berbagai faktor dapat mempengaruhi pertumbuhan modal sendiri suatu perusahaan. Untuk mengetahui faktor faktor yang mempengaruhi pertumbuhan modal sendiri dapat diamati dengan mengembangkan suatu model dimana pertumbuhan modal sendiri merupakan variabel dependen dengan aspek-aspek keuangan sebagai variable independen.

\section{Hipotesis}

Gambar 1. Model Penelitian

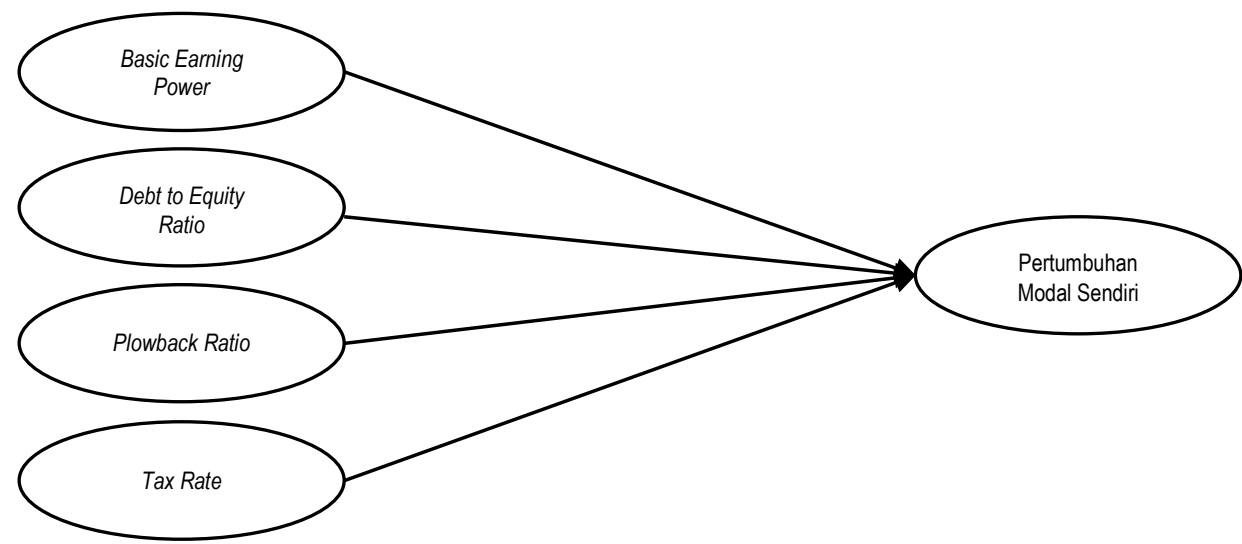

Berdasarkan uraian latar belakang, kajian literatur, dan model penelitian di atas, maka dapat dirumuskan hipotesis penelitian ini sebagai berikut:

Hipotesis 1 : Basic Earning Power, Debt to Equity Ratio, Plowback Ratio, Interest dan Tax Rate, secara simultan berpengaruh signifikan terhadap pertumbuhan modal sendiri

Hipotesis 2 : Basic Earning Power, Debt to Equity Ratio, Plowback Ratio, Interest dan Tax Rate, secara parsial berpengaruh signifikan terhadap pertumbuhan modal sendiri

Hipotesis 3 : Basic Earning Power berpengaruh dominan terhadap pertumbuhan modal sendiri

\section{Metode Penelitian}

Penelitian ini menggunakan pendekatan kuantitatif dengan menggunakan alata analisis data regresi berganda, untuk mendapatkan data dilakukan dengan cara dokumentasi melalui akses di Bursa Efek Indonesia. Sampel dalam penelitian ini adalah perusahaan rokok yang terdaftar di Bursa Efek indonesia.tahun 2013 -2018. Variabel dependen dalam penelitian ini adalah pertumbuhan modal sendiri yang diukur dengan membandingkan antara perubahan modal sendiri dengan modal sendiri pada periode tahun lalu (t-1) dengan satuan persentase, sedangkan variabel independen di dalam penelitian ini adalah Basic Earning Power, Debt to Equity Ratio, Plowback Ratio dan Interest and Tax Rate. Teknik analisis yang digunakan di dalam penelitian ini adalah regresi linier berganda.

\section{Hasil Penelitian}

Hasil Analisis Regresi Linier Berganda dapat kita lihat pada tabel 1 berikut:

Tabel 1. Hasil Uji ANOVA

\begin{tabular}{lllllll} 
Model & & Sum of & Df & Mean Square & $F$ & Sig \\
& & Square & & & & \\
\hline 1 & Regression & 1,871 & 4 & 0,898 & 13,714 & $0,003^{(a)}$ \\
& Residual & 2,513 & 1923 & 0,037 & & \\
& Total & 4,384 & & & & \\
\hline
\end{tabular}

Sumber: Data sekunder diolah, 2019. 
Hasil analisis regresi linier berganda menunjukkan bahwa variabel-variabel independen yaitu basic earning power (EP), debt to equity ratio (DE R). plowback ratio (PR). interest and tax rate (ÍTR) secara simultan berpengaruh signifikan terhadap pertumbuhan modal sendiri $(\mathrm{g})$ dengan nilai sig $\mathrm{F} 0,003$, sehingga hipotesis pertama terbukti.

Tabel 2. Coefficients

\begin{tabular}{|c|c|c|c|c|c|c|}
\hline \multirow[t]{2}{*}{ Model } & & \multicolumn{2}{|c|}{ Unstndardized Coefficients } & $\begin{array}{l}\text { Standardized } \\
\text { Coefficients }\end{array}$ & \multirow[t]{2}{*}{$\mathrm{t}$} & \multirow[t]{2}{*}{ Sig } \\
\hline & & B & Std. Error & Beta & & \\
\hline 1 & (Constan) & 0,981 & 0,052 & & 1,527 & 0,159 \\
\hline & EP & 1,163 & 0,646 & 0,495 & 1,801 & 0,088 \\
\hline & DER & 0,036 & 0,017 & 0,273 & 2,983 & 0,017 \\
\hline & PR & 0,027 & 0,010 & 0,320 & 3,110 & 0,041 \\
\hline & ITR & -324 & 0,171 & -321 & $-3,610$ & 0,032 \\
\hline
\end{tabular}

Sumber: Data Sekunder diolah, 2019

Sementara jika dilihat dari pengaruh secara parsial (dalam tabel 2 ) hanya variabel Basic Earning Power yang tidak berpengaruh signifikan terhadap pertumbuhan modal sendiri dengan sig $5 \%$, ini menunjukkan hipotesis kedua tidak terbukti karena masih ada variabel yang tidak signifikan pengaruhnya.. Koefisien beta variabel basic earning power (X1) paling tinggi diantara variabel dependen yang ada, sehingga bisa dikatakan variabel basiv earning power mernpunyai pengaruh yang paling dominan terhadap pertumbuhan modal sendiri pada perusahaan rokok go public yang terdaftar di Bursa Efek Indonesia. Hasil ini ditunjukkan dengan koefisien beta terbesar yaitu 0.495. Pengaruh earning power terhadap laju pertumbuhan tidak signifikan pada alfa $5 \%$ namun signifikan pada alfa $10 \%$ Hipotesis ketiga yang menyatakan basic earning power berpengaruh dominan terbukti. Hal ini menunjukkan bahwa semakin tinggi kemampuan perusahaan menghasilkan laba dari aktiva yang digunakan maka kemungkinan untuk rneningkatkan retained earning (laba ditahan) juga semakin besar sehingga dapat rnengakibatkan meningkatnya pertumbuhan modal sendiri.

\section{Pembahasan}

Munawir (2010) menyebutkan modal adalah hak atau bagian yang dimiliki oleh pernilik perusahaan yang ditunjukkan dalam pos modal (modal saham), surplus dan laba yang ditahan, atau kelebihan nilai aktiva yang dimiliki oleh perusahaan terhadap seluruh utang-utangnya. Modal sendiri adalah modal yang berasal dan pemilik perusahaan yang tertanam di dalam perusahaan untuk jangka waktu yang tidak tentu lamanya (Riyanto, 2008). Modal sendiri akan mengalami peningkatan jika perusahaan mampu meningkatkan profitabilitasnya, karena tingginya laba setelah pajak akan memberi kesempatan perusahaan untuk meningkatkan modal sendiri (jika laba tidak dibagikan sebagai deviden)

Hasil penelitian menunjukkan bahwa secara simultan variabel basic earning power (EP). debt to equity ratio (DER), plowback ratio (PR), serta interest and tax rate (ITR) berpengaruh signifikan terhadap laju pertumbuhan modal sendiri. Penelitain ini mendukung hasil penelitian Waskito (2008) yang menemukan bahwa variabel basic earning power (EP). debt to equity ratio (DER), .plowback ratio (PR), serta interest and tax rate (ITR) secara simultan berpengaruh terhadap I aju peetumbuhan modal sendiri. Dengan variabel tambahan Return on Investment penelitian Rosana (2010) menemukan hal yang sama bahwa variabel basic earning power (EP). debt to equity ratio (DER),.plowback ratio (PR), interest and tax rate (ITR) dan return on investmen secara simultan berpengaruh signifikan terhadap laju pertumbuhan modal sendiri, Sementara penelitian Tanjung(2014) dengan satu variabel yang berbeda yakni sales growth menunjukkan hasil yang sama bahwa faktor internal yang terdiri dari basic earning power, debt to total equity sales growth dan tax rate secara simultan berpengaruh terhadap laju pertumbuhan modal sendiri. Sementara secara parsial tidak semua variabel berpengaruh signifikan terhadap lajur pertumbuhan modal sendiri, hasil ini sejalan dengan penelitian waskito (2008), namun ada perbedaan variabel yang berpengaruh tidak signifikan dalam penelitian ini hanya basic earning power sementara di penelitian Waskito(2008) yang berpengaruh signifikan hanya plowback ratio. 
Pada hakekatnya aktivitas pemenuhan dan peggunaan dana menyangkut keseimbangan financial dalam perusahaan yaitu keseimbangan aktiva dengan pasiva yang dibutuhkan beserta mencari susunan kualitatif dan aktiva dan pasiva tersebut dengan sebaik-baiknya. Pemilihan susunan kualitatif aktiva akan menentukan struktur kekayaan perusahaan sedangkan pemilihan susunan kualitatif pasiva akan menentukan struktur finansial dan struktur modal perusahaan. Struktur modal merupakan perimbangan antara hutang jangka panjang dengan modal sendiri yang digunakan oleh perusahaan. Ketentuan umurn (rule of Thumb) berkaitan dengan struktur modal menyatakan bahwa perbandingan antara hutang jangka panjang dengan modal sendiri tidak boleh lebih dan 1:1. Struktur modal perusahaan rokok go public yang terdaftar di Bursa Efek Indonesia seperti terlihat dalam Tabel 3

Tabel 3. Struktur Modal perusahaan Rokok yang Go Publik di Bursa Efek Indonesia tahun 2013 - 2018

\begin{tabular}{ccccccc} 
Perusahaan & \multicolumn{5}{c}{ Kondisi Struktur Modal } \\
\cline { 2 - 7 } & 2013 & 2014 & 2015 & 2016 & 2017 & 2018 \\
\hline HMSP & $1: 12$ & $1: 11$ & $1: 7$ & $1: 16$ & $1: 14$ & $1: 14$ \\
GGRM & $1: 23$ & $1: 19$ & $1: 19$ & $1: 22$ & $1: 21$ & $1: 23$ \\
RMBA & $4: 1$ & $4: 1$ & $4: 1$ & $1: 23$ & $1: 18$ & 1 is: 17 \\
WIIM & $1: 20$ & $1: 29$ & 116 & $1: 14$ & $1: 11$ & $1: 10$ \\
\hline
\end{tabular}

Sumber: Data Sekunder diolah, 2019

Dari Tabel 3 terlihat keempat perusahaan rokok memiliki struktur modal yang baik karena perbandingan antara hutang dengan modal tidak lebih dari 1:1 (kecuali PT Bentoel yang memiliki struktur modal tahun 2013 s/d tahun 2015 diatas 1: 1. Kondisi yang semakin baik yang terjadi pada PT Bentoel tahun 2016 terus meningkat sejalan dengan perusahaan lainnya, dimana stryktur modal masih dibawah $1: 1$, artinya total modal sendini masih lebih besar dan total hutang jangka panjang. Ini akan berpengaruh terhadap operasional karena keempat perusahaan tersebut mampu menutup hutang jangka panjang dengan menggunakan modal sendiri. Faktor-faktor yang mempengaruhi pertumbuhan modal sendiri terdiri dan (Brigham. 1996:184): basic earning power (EP). debt to equity ratio (DER), plowback ratio (PR), serta interest and tax rate (ITR). Faktor-faktor yang mempengaruhi pertumbuhan modal sendiri terdiri dan (disarikan dalam. Menurut Hopkin (1937) dalam Handini (1996) faktor - faktor yang mempengaruhi pertumbuhan modal sendiri antara lain return on assel (ROA), debt to equity ratio (DER), retentalion rate (plowback ratio), tingkat bunga, dan tingkat pajak.

Berdasar hasil penelitian menunjukkan bahwa secara simultan variabel basic earning power (EP). debt to equity ratio (DER), plowback ratio (PR), serta interest and tax rate (ITR) berpengaruh secara signifikan terhadap pertumbuhan modal sendiri. Sementara jika dilihat secara parial masih ada variabel yang berpengaruh tidak signifikan, hal ini disebabkan karena beberapa hal. Untuk perusahaan rokok tidak signifikan kemungkinan dikarenakan laba yang digunakan adalah (earning before interest and tax) EBIT, karena jika menggunakan EBIT maka pengeluaran perusahaan yang relatif besar (pajak) tidak mengurangi EBIT, sehingga EBIT tidak berpengaruh secara langsung terhadap besarnya modal perusahaan. EBIT merupakan laba yang dikurangi oleh besarnya biaya bunga dan pajak yang ditanggung oleh perusahaan, sementara yang mempengaruhi besarnya modal sendiri secara langsung adalah EAT (earning after tax), karena earning after tax inilah yang nantinya akan menjadi sumber tambahan modal sendiri bagi perusahaan, yang akan mempengaruhi pertumbuhan modal sendiri tersebut.

Selain faktor pajak diatas ketidaksignifikanan hasil analisis statistik yang dilakukan pada perusahaan rokok secara parsial karena perusahaan rokok mengeluarkan biaya pajak yang cukup tinggi, yang tentunya akan berpengaruh pada EAT dan selanjutnya akan mempengaruhi besarnya modal sendiri. Alasan lainnya adalah karena deviasi nilai (penyimpangan nilai) variabel yaitu nilai basic earning power (EP) antara PT. HM Sampurna berbeda sangat besar dengan PT. Bentoel International Investama. Nilai basic earning power PT. HM. Sampurna sebesar 0,2892, sementara nilai basic earning power PT. Bentoel International Investama $-0,0411$. Hal ini menyebabkan pengaruh basic earning power tidak signifikan terhadap laju pertumbuhan modal kerja.

\section{Kesimpulan}

Berdasarkan hasil penelitian yang telah dilakukan, dapat disimpulkan bahwa variabel independen Basic Earning Power (EP), Debt to Equity Ratio (DER), Plowback Ratio (PR), serta Interest and Tax Rate (ITR) secara simultan 


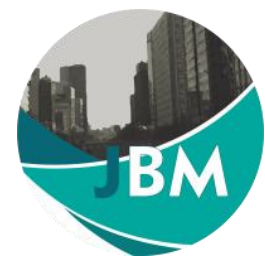

berpengaruh signifikan terhadap laju pertumbuhan modal sendiri, sementara secara parsial basic earning power tidak berpengaruh secara signifikan terhadap laju pertumbuhan modal sendiri. Variabel Basic Earning Power berpengaruh dominan terhadap laju pertumbuhan modal sendiri.

Berdasarkan hasil penelitian tersebut, maka peneliti dapat memberikan saran agar laju pertumbuhan modal sendiri bisa ditingkatkan, perusahaan harus bisa meningkatkan keuntungan yang diperoleh dengan cara meminimalisir penggunaan hutang dan peningkatan pendapatan. Bagi Peneliti Lanjutan Untuk penelitian selanjutnya sebaiknya periode penelitian yang digunakan ditambah sehingga menghasilkan informasi yang lebih mendukung. Gunakan earning after tax (EAT) sebagai indikator pembanding dalam penelitian selanjutnya.

\section{Daftar Pustaka}

Brigham, Eugene F. (1996). Intermediate Financial Management. 5th edition. The Dryden Press.

Handini, Sri. (1996). Analisis Fakior-fakior yang Meinpengaruhi Laja Pertumbuhan Modal Sendiri pada Industri Barang-barang Konsumsi yang Terdaftar di BEJ tahun Penganatan ¡992-1994. Tesis Program Pasea Saijana UGM. Yogyakarta.

Maryati. (2001). Analisis Fakior-fakior yang Mempengaruhi Laju Pertumbuhan Modal Sendiri pada Perusahaan Industri Semen yang Terdaftar di BEJ, Jurnal Telah Bisnis Vol 2.

Munawir. (2010) Analisa Laporan Keuangan, Liberty, Yogyakarta.

Riyanto, Bambang. (2008). Dasar-dasar Pembelajaran Perusahaun, Edisi 4, BPFE, Yogyakarta.

Rosana, Ruth. (2010) Analisis faktor-faktor yang mempengauhi pertumbuhan modal sendiri pada perusahaan real estate \& building construction, Jurnal Ekonomi Vol 12 No 3 Juli 2010. USU, Medan. repository.USU.ac.id

Tanjung, Gusni. (2014) Analisis faktor- faktor yang mempengaruhi pertumbuhan modal sendiri pada industry real estate dan konstruksi bangunan. Seminar Nasional Ekonomi, Manajemen dan Akuntansi (Snema) 2014, Fakultas Ekonomi Universitas Padang, www.researcggate.net.

Waskito, Dian. (2008) Analisis faktor faktor yang mempengaruhi pertumbuhan modal sendiri perusahaan manufaktur yang terdaftar di Bursa efek Indonesia, Tesis, Universitas Sumatera Utara, Medan. repository.USU.ac.id 